\title{
Biosorptive Removal of Hexavalent Chromium by Rice Husk Ash and Silica from Aqueous Solution
}

\author{
*Adelagun ROA, Etim EE, Ushie OA, Kamba AE, Aikhoje EF \\ Department of Chemical Sciences, Federal University Wukari, Taraba, Nigeria.
}

\begin{abstract}
Hexavalent chromium ion removal by adsorption using rice husk ash and silica prepared from rice husks obtained locally from rice mill as biosorbents was evaluated as low cost wastewater treatment in this study. Batch equilibrium isotherm experiments were performed as well as effect of dosage and initial chromate solution $\mathrm{pH}$ to determine the potentials of the sorbent to remove hexavalent chromate ion from synthetic fed wastewater. Equilibrium isotherm experimental data isotherms were tested with isotherm models (Langmuir, Freundlich and Tempkin models), being best represented by the Langmuir model. Optimum conditions were: dosage $=0.5 \mathrm{~g} / 200$ $\mathrm{ml}$ at room temperature and $\mathrm{pH}_{\mathrm{o}}>6$. The equilibrium between adsorbate in the solution and on the adsorbent surface was practically achieved in $2 \mathrm{~h}$. The monolayer sorption capacity was $67.45 \mathrm{mg} / \mathrm{g}$ for rice husk silica and $55.98 \mathrm{mg} / \mathrm{g}$ for rice husk ash. Estimation of energy of the sorption process revealed chemisorption as the prevailing means of interaction between the adsorbents and adsorbates moieties. The abundance and affordable (cheap) cost of rice husks justifies its use as a precursor in the preparation of rice husk ash and silica as effective adsorbents for chromium removal from industrial effluents.
\end{abstract}

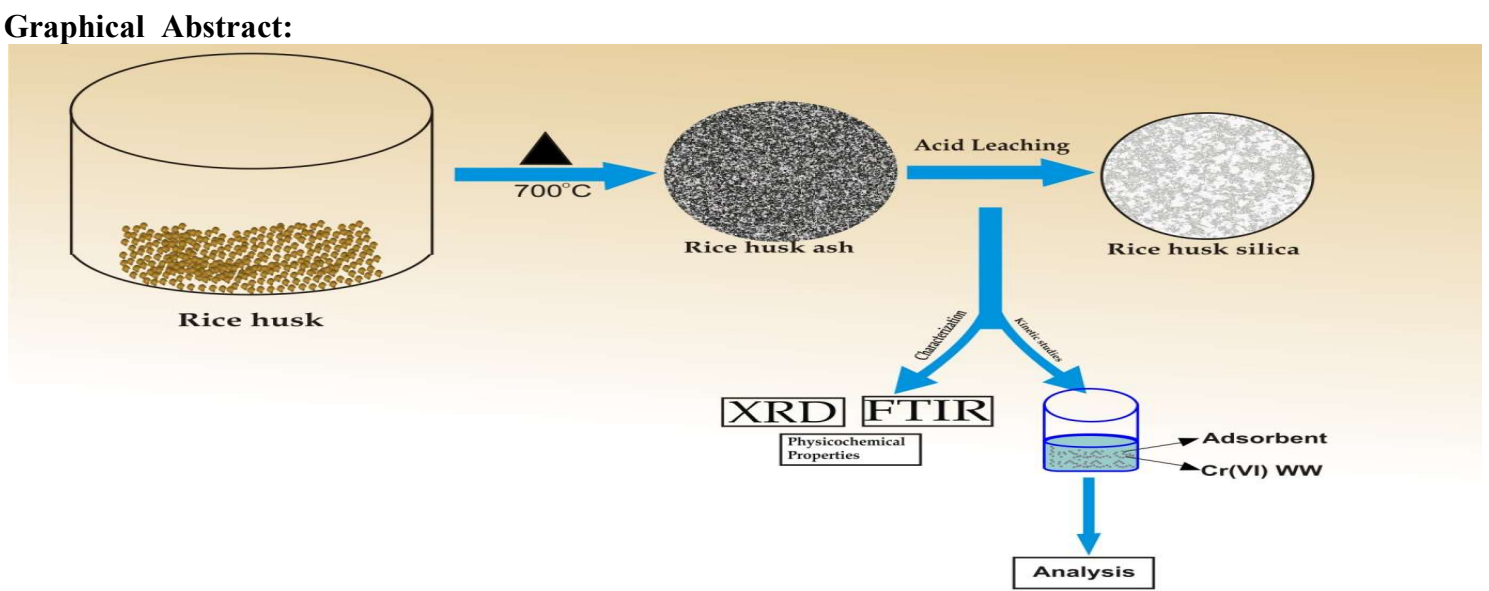

Keywords:Hexavalent chromium, Biosorption, Isotherm, Rice husk ash, Rice husk silica

DOI: $10.7176 / \mathrm{CMR} / 13-1-02$

Publication date: January $31^{\text {st }} 2021$

\section{Introduction}

Biosorptive treatment of wastewater involves the use of biological materials via a metabolically - mediated physicochemical pathways to accumulate and sorb the inherent pollutants. This technique is an environmental cleanup practice used by Scientists and Water Engineers to provide an economical alternative for removing toxic wastes including heavy metals, pesticides and other organic compounds which can be toxic to wildlife and humans in small concentration from industrial effluents. Biosorption technique can be simply defined as the passive binding (uptake) of pollutants by dead or living biomass (Gupta and Rostagi, 1999). The use of dead biomass as biogenic materials or biosorbent has proven to provide some advantages over the live biomass; absence of nutrient needs for growth, higher sorption capacity, simple operation, low operational cost and ease of regeneration of biomass. Use of living biomass may lead to their death or toxicity after pollutant accumulation, growth of living biomass may become impaired and increased cost incurred as a result of continuous supply of nutrients to the biomass (Ofomaja et al., 2010). Hence, the use of dead biomass is economical. These biosorbents can effectively sequester metal ions in the solution and decrease the concentration from the ppm to ppb level efficiently.

Abundant natural materials like microorganisms (microbial, bacterial, fungal), plant-derived (algal biomass, lignocellulosic materials), biopolymers (e.g. chitosan), and industrial by-products, have been suggested as potential biosorbents for heavy metal removal due to the presence of metal-binding functional groups. The mechanisms of interaction between the cell wall of the biomass and the pollutant could be physical and / or chemical. The process involves binding of ions onto the functional groups present on the surface of the biosorbent in aqueous solutions by means of various interactions: complexation, ion exchange, precipitation etc, rather than 
oxidation through aerobic or anaerobic metabolism (Gupta et al., 2010). Biosorption is influenced by various process parameters such as $\mathrm{pH}$, temperature, initial concentration of the metal ions, biosorbent dose and speed of agitation. Rice milling generates a by-product know as husk which is about $22 \%$ of the rice paddy. Rice husk accounts for about one-fifth of the annual gross rice production. The rice husk is traditionally considered as a waste material and as such is generally disposed of by dumping, burning or used as a low-grade fuel. During controlled firing and proper conditions, $1 / 4(\mathrm{w} / \mathrm{w})$ of the husk is usually converted to rice husk ash made up of about $90 \%$ amorphous silica of a very high purity. Advantages such as low cost, abundance, availability and possibility of regeneration and reuse have greatly favoured the application of rice husk in the removal of pollutants including heavy metals in aqueous solution in recent times (Viere et a.1,2010; Gibb et al., 2009)

Presence of chromium in the environment is due to its extensive used in variety of industrial applications: mining operations, leather tanning, steel production units, power generation, cement industries, mining, metal plating and so on (Gupta and Rostagi, 1999). Chromium occurs in several different oxidation states that ranges between -2 and +6 , with the +3 and +6 states been the stable forms in the natural environments. Chromium (VI) is highly mobile in the environment and very toxic. $\mathrm{Cr}$ (VI) can easily penetrate the cell wall; chronic exposure can lead to mutagenesis and carcinogenesis (Gibb et al., 2010). The highest level of Cr (VI) ions permitted in a discharge into inland surface and potable water, are 0.1 and $0.05 \mathrm{mg} / \mathrm{L}$, respectively (Mojdeh et al., 2009; EPA, 1990). Various physico-chemical methods have been studied and tested for detoxification and removal of chromium-laden waste waters in the recent years. Among these are phytoremediation, ion exchange, chemical reduction, solvent extraction, precipitation, liquid membrane, reverse osmosis, etc. However, they have high operating costs and problems in the disposal of the residual metal sludges (Mutongo et al., 2014). The economic recovery of chromium from wastewater is essential in minimising its environmental impact. This study is therefore aimed at hexavalent chromium removal from industrial effluent using rice husk ash and silica prepared from locally obtained rice husks wastes in a batch sorption study via equilibrium isotherm process. The effect of dosage and $\mathrm{pH}$ on the process shall be examined.

\section{Experimental}

\section{(a) Materials}

\section{i. Preparation of Rice Husk Ash (RHA)}

The Rice Husk was collected from a nearby rice mill without any pretreatment except sieving to remove dirt and washed several times with deionized water to remove surface particles and dried in an open air. Rice husk ash was prepared from the dried rice husk by calcination in a muffle furnace (CARBOLITE, 5220) and acid leaching using nitric acid (Analar grade). Acid leaching of rice husk was done to remove soluble elemental impurities and increase the purity of silica content. $60 \mathrm{~g}$ of the rice husk was soaked in $120 \mathrm{ml}$ of concentrated $37 \%$ hydrochloric acid and heated at $100^{\circ} \mathrm{C}$ for $30 \mathrm{~min}$. Rice husk was filtered and rinsed for several times with distilled water until neutral $\mathrm{pH}$ and dried at $100{ }^{\circ} \mathrm{C}$ for $2 \mathrm{~h}$. The rice husk ash was obtained by pyrolysis of the rice husk in a muffle furnace at $700{ }^{\circ} \mathrm{C}$ for $6 \mathrm{~h}$ in the form of a white-grey powder.

\section{ii. Preparation of Rice Husk Silica}

The chemicals and reagents used in the process were of analytical grade. RHS preparation carried out by the addition of $35 \mathrm{~g}$ of the rice husk ash powder into $250 \mathrm{ml}$ of $1 \mathrm{~N} \mathrm{NaOH}$, followed by vigorous stirring and allowed to stand for $12 \mathrm{~h}$ to produce sodium silicate. The sodium silicate solution was filtered to remove undissolved materials and then titrated drop-wise with $3 \mathrm{M} \mathrm{H}_{2} \mathrm{SO}_{4}$ until a final $\mathrm{pH} 5$ was obtained. The soft gel formed was aged for 4 days, filtered through suction filtration, washed with distilled water and dried in the oven at $110^{\circ} \mathrm{C}$ for $24 \mathrm{~h}$ and then calcined in the muffle furnace at $700^{\circ} \mathrm{C}$ for $5 \mathrm{~h}$ to produced rice husk silica. The acidic condition of pH 5 indicates approximately the complete precipitation of silica from sodium silicate by the following reaction:

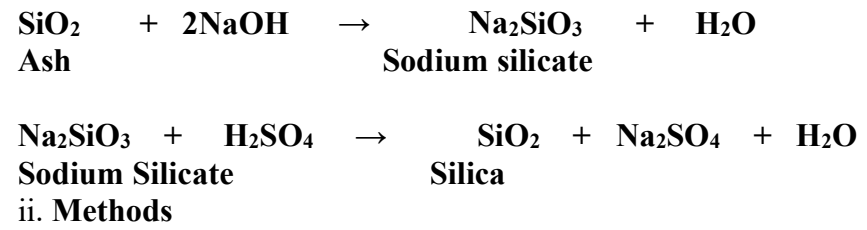

\section{a. Preparation and analysis of adsorbate}

Hexavalent chromium stock solution of known concentration $(1000 \mathrm{mg} / \mathrm{L})$ was prepared in a double distilled deionized water using potassium dichromate $\left(\mathrm{K}_{2} \mathrm{Cr}_{2} \mathrm{O}_{7}\right)$ salt. Varying concentrations $(10-200 \mathrm{mg} / \mathrm{L})$ was prepared from the stock as working solutions by serial dilution.. The residual $\mathrm{Cr}$ (VI) concentration in the solution was determined spectrophotometrically at $\lambda=540 \mathrm{~nm}$ using a UV - visible spectrophotometer (UV-1601, Shimadu) following the 1,5 -diphenylcarbazide procedure.

b. Data analysis

The amount of chromium sorbed per unit mass of the adsorbent $(\mathrm{mg} / \mathrm{g})$ was calculated using the mass balance 
equation:

$q_{e}=\frac{c_{o}-c_{e}}{w} \times v$

In which $q_{e}$ is the amount of chromium sorbed $(\mathrm{mg} / \mathrm{g}), \mathrm{c}_{\mathrm{o}}$ is the initial chromium concentration $(\mathrm{mg} / \mathrm{L}), \mathrm{c}_{\mathrm{e}}$ is the equilibrium chromium concentration $(\mathrm{mg} / \mathrm{L}), v$ is the volume of the solution $(\mathrm{ml})$ and $w$ is the mass of the adsorbent (g).

Percentage metal ions removal $=\frac{c_{o}-c_{e}}{c_{o}} \times 100$

c. Determination of Point of Zero Charge

The point of zero charge of the adsorbents was determined by adopting the solid addition method via: $45 \mathrm{ml} \mathrm{KNO}_{3}$ solutions of known strength were transferred into five (5) sets of $100 \mathrm{ml}$ conical flasks. The $\mathrm{pH}_{\mathrm{o}}$ values of the solutions were roughly adjusted using either $0.1 \mathrm{M} \mathrm{HNO}_{3}$ or $\mathrm{NaOH}$ to vary between $\mathrm{pH}=2$ and $\mathrm{pH}=12$. The total volume of the solution in each flask was then made up to $50 \mathrm{ml}$ by adding the $\mathrm{KNO}_{3}$ solution of the same strength. The $\mathrm{pH}_{\mathrm{o}}$ of the solutions were accurately noted. $1 \mathrm{~g}$ of the adsorbent was added to each flask and immediately securely capped. The mixture was then manually agitated and allowed to equilibrate for $48 \mathrm{~h}$ with intermittent manual after which the final $\mathrm{pH}_{\mathrm{f}}$ was noted. The difference between the initial and final $\mathrm{pH}\left(\Delta \mathrm{pH}=\mathrm{pH}_{0}-\mathrm{pH}_{\mathrm{f}}\right)$ values was plotted against the $\mathrm{pH}_{0}$. The point of intersection of the resulting curve on $\mathrm{pH}_{0}$ gave the point of zero charge.

\section{d. Determination of Surface Area}

The method designed for surface area of siliceous material by Sears, 1956 was adopted in this experiment. To a $100 \mathrm{ml}$ dilute $\mathrm{HCl}(\mathrm{pH}=3), 1.5 \mathrm{~g}$ of the sample was added, followed by $30 \mathrm{~g}$ of $\mathrm{NaCl}$ with continuous stirring and made up to $150 \mathrm{ml}$ using distilled water. This was followed by titration of the solution against $0.1 \mathrm{~N} \mathrm{NaOH}$. The amount of volume $(\mathrm{V})$ of $\mathrm{NaOH}$ needed to raise the $\mathrm{pH}$ from 4 to 9 was then noted. The procedure was repeated and the average volume was taken for the calculation of the surface area. The surface area was calculated using the equation:

$S=32 \mathrm{~V}-25$

with, $\mathrm{S}=$ Surface area $\left(\mathrm{m}^{2} / \mathrm{g}\right)$ and $\mathrm{V}=$ Average volume of $\mathrm{NaOH}$ Needed.

e. Batch Adsorption Experiments

All sorption studies were done and carried out at $25^{\circ} \mathrm{C}$. Adsorbate solution $\mathrm{pH}$ was corrected to 5.3 using $0.1 \mathrm{M}$ $\mathrm{HNO}_{3}$ and $\mathrm{NaOH}$.

\section{i. Equilibrium Isotherm Studies}

The isotherm studies were carried out by contacting $200 \mathrm{ml}$ aqueous solution of known concentration of the adsorbate that ranged between $10-200 \mathrm{mg} / 1$ in a $250 \mathrm{ml}$ borosilicate conical flask containing $0.4 \mathrm{~g}$ of the adsorbent. The flask was agitated at a constant rate of $200 \mathrm{rpm}$ using a magnetic stirrer for a period of time after equilibrium is established. At the expiration of this period, the samples were withdrawn using a syringe, centrifuged at 5000 rpm for $5 \mathrm{~min}$ and then the supernatant liquid was analyzed for residual concentration of chromium using UVvisible. The amount sorbed per unit mass of the adsorbent (in $\mathrm{mg} / \mathrm{g}$ ) was calculated by using equation (1)

\section{ii) Effect of adsorbent dosage.}

The effect of the adsorbent dose on the sorption process was investigated at different adsorbent dosages of 0.2 $1.0 \mathrm{~g}$ by contacting with $100 \mathrm{ml}$ of known concentration of the adsorbate that ranged between $10-200 \mathrm{mg} / 1 \mathrm{in} \mathrm{a}$ $250 \mathrm{ml}$ borosilicate conical flask and agitated at a constant rate of $200 \mathrm{rpm}$ using a magnetic stirrer. The contact time was kept at $2 \mathrm{~h}$, since equilibrium was found to have been attained at $2 \mathrm{~h}$ contact time. Residual chromate concentration was determined as described above.

\section{iii. Effect of initial adsorbate solution $\mathbf{p H}$}

The effect of $\mathrm{pH}_{\mathrm{o}}$ on the sorption was studied by adjusting the initial adsorbate solution $\mathrm{pH}\left(\mathrm{pH}_{\mathrm{o}}\right)$ to range between $\mathrm{pH}=2-10$ using $0.1 \mathrm{M} \mathrm{HCl}$ or $\mathrm{NaOH}$ and measured with a $\mathrm{pH}$ meter. For this experiment, the adsorbent loading was kept at $0.1 \mathrm{~g}$ per $50 \mathrm{ml}$ of known concentration of adsorbate solution and agitated at $200 \mathrm{rpm}$ at ambient temperature. The contact time was kept at $2 \mathrm{~h}$, since equilibrium was found to have been attained at $2 \mathrm{~h}$ contact time. Residual chromate concentration was determined as described above.

\section{Results and Discussion}

\section{a. Equilibrium Isotherm Analysis}

Equilibrium Isotherm analysis of a sorption process gives insight into the affinity of an adsorbent for an adsorbate. Adsorption equilibrium isotherm studies are described by sorption isotherm characterized by certain constants and parameters whose values express the surface properties and affinity of the adsorbents for the adsorbates [2]. Elucidation into the mechanism of adsorption process is obtained via the use of adsorption models. Design and optimization of an adsorption system is hinged on the data obtained from the equilibrium curves. The experimental data of the equilibrium isotherm studies of chromium ion sorption onto the two adsorbents used in this study (RHA and RHS) were fitted into three common equilibrium isotherm models namely, Freundlich, Langmuir and Tempkin equations. 
The Freundlich isotherm model regarded as an empirical isotherm with no theoretical basis, hints that the adsorption occurs on a heterogeneous adsorbent surfaces and sites of varying affinities and binding strength. It assumes that the stronger sites are firstly occupied and can be applied to multilayer adsorption (Adelagun et al., 2014; Mohanty et al., 2009). The linearized form of Freundlich equation is:

$\log q_{e}=\frac{1}{n} \log c_{e}+\log k_{f}$

With $n$ and $k f$ being Freundlich coefficients. For a favourable sorption, the value of $n$ should lie between 1-10, while a high $k f$ value denotes a high affinity of the adsorbent for the adsorbate.

The Langmuir isotherm model is valid for monolayer adsorption onto a surface containing a finite number of identical and homogeneous sites. The model assumes uniform energies of adsorption sites on the adsorbent surface and no transmigration of adsorbate in the plane of the surface (Nakbantote et al., 2007). The linearized form is presented as:

$\frac{1}{q_{e}}=\frac{1}{q_{m}}+\frac{1}{b q_{m c_{e}}}$

With $c_{e}$ and $q_{e}$ being the concentration of chromium at equilibrium in the liquid $(\mathrm{mg} / \mathrm{L})$ and solid phase $(\mathrm{mg} / \mathrm{g})$, respectively, $b(\mathrm{~L} / \mathrm{g})$ and $q_{m}(\mathrm{mg} / \mathrm{g})$ are the Langmuir equilibrium constant and the maximum adsorption capacity on a monolayer of the adsorbent active surface, respectively. The magnitude of $b$ expresses the affinity between the adsorbent and adsorbate and is largely determined by the heat of sorption. An isotherm process is described to be favourable if the sorption capacity of the adsorbent increases with increase in initial concentration of the adsorbate 9 Weber and Chakravorti, 1974). A dimensionless constant known as equilibrium parameter $\left(R_{L}\right)$ or separation factor is generally used to describe the nature of a Langmuir isotherm as either unfavourable $\left(R_{L}>\right.$ 1), linear $\left(R_{L}=1\right)$, Favourable $\left(0<R_{L}<1\right)$ or irreversible $\left(R_{L}=0\right)$ and calculated as (eqn.6) with $b$ as the Langmuir constant and $c_{o}$ as the initial chromate concentration:

$R_{L}=\frac{1}{1+b c_{o}}$

The Tempkin isotherm model studies the interactions between adsorbent and adsorbate and the free energy of adsorption as a function of surface coverage. The linear form of the Temkin isotherm model equation is given as: $q_{e}=B_{T} \ln A+B_{T} \ln C_{e}$

where $B_{T}(\mathrm{~J} / \mathrm{mol})$ corresponds to Temkin isotherm constant, the heat of adsorption and $A(1 / \mathrm{g})$ is the equilibrium binding constant corresponding to the maximum binding energy. A high value of $A$ and $B_{T}$ indicates a strong bonding and fast sorption of the adsorbate on the adsorbent surface. The related isotherm parameters are presented in Table 1. The maximum sorption capacity $\left(q_{m}\right)$ observed for both adsorbents were quite high in comparisons with some adsorbents reported in literatures for hexachromate ions removal (Mutongo et al., 2009, Dubey and Gopal 2007; Baral et al., 2006; Babu and Gupta, 2008; Karthikeyan et al., 2004; Crimono et al., 2000). The monolayer sorption capacity, $q_{m}$ for RHS was higher $(67.45 \mathrm{mg} / \mathrm{g})$ than for RHA $(55.98 \mathrm{mg} / \mathrm{g})$. Probable reason for this difference could be attributed to the differences in their surface areas. The surface area of RHS as determined by Sear's method was $21.55 \mathrm{mg}^{2} / \mathrm{g}$ while RHA was $15.72 \mathrm{mg}^{2} / \mathrm{g}$. The value of $b(\mathrm{~L} / \mathrm{mg})$, the Langmuir constant indicates the heat of biosorption, is higher for RHS (0.065) than for RHA (0.043). The $R_{L}$ values calculated using equation (6), showed favourable sorption process for all initial concentrations used. Calculated values of $R_{L}$ values obtained showed favourable sorption of chromium ion onto the adsorbents. The $R_{L}$ values decreased from 0.078 to 0.028 for RHA and 0.02 to 0.015 for RHS as the initial concentration was increased from 10 to $200 \mathrm{mg} / \mathrm{L}$. These extremely low values of $R_{L}$ are indications that the process is favourable. The Freundlich parameter $n$, an indication of the sorption intensity for the adsorbate by the adsorbent was high: RHS $=4.50$, RHA $=3.20$, an indication of strong intensity between adsorbents and adsorbate and strong bond formation. These two factors ( $n$ and $R_{L}$ ) thus suggest a favourable sorption process between the adsorbents and adsorbate. The high Freundlich constant $\mathrm{k}_{\mathrm{f}}$, suggests high affinity between $\mathrm{Cr}(\mathrm{VI})$ and the adsorbents RHS and RHA as shown in Table I. The values obtained for the Tempkin parameters $\left(B_{T}\right.$ and $\left.A\right)$ showed high heat of sorption and binding energy.

Table I: Equilibrium Isotherm Models Parameters of Cr (VI) sorption on RHA and RHS

\begin{tabular}{|c|c|c|c|c|c|c|}
\hline \multirow[t]{2}{*}{ Isotherm Model } & \multicolumn{3}{|c|}{ RHA } & \multicolumn{3}{|c|}{ RHS } \\
\hline & $q_{m}$ & $\boldsymbol{k}_{l}$ & $r^{2}$ & $q_{m}$ & $k_{f}$ & $r^{2}$ \\
\hline Langmuir & 55.98 & 0.043 & 0.9711 & 67.45 & 0.065 & 0.9792 \\
\hline & $n$ & $\boldsymbol{k}_{f}$ & $r^{2}$ & $n$ & $\boldsymbol{k}_{f}$ & $r^{2}$ \\
\hline Freundlich & 3.2301 & 6.11 & 0.9025 & 4.5097 & 10.382 & 0.8968 \\
\hline Tempkin & $\begin{array}{c}\boldsymbol{B}_{\boldsymbol{T}} \\
100.34\end{array}$ & $\begin{array}{c}\boldsymbol{A} \\
267.4\end{array}$ & $\begin{array}{c}r^{2} \\
0.825\end{array}$ & $\begin{array}{c}\boldsymbol{B}_{T} \\
196.22\end{array}$ & $\begin{array}{c}A \\
A 63.8\end{array}$ & $\begin{array}{c}r^{2} \\
0.7999\end{array}$ \\
\hline
\end{tabular}

The assessment of the suitability of the isotherm models to describe the process was examined by the evaluation of their linear coefficient of determination $\left(\mathrm{R}^{2}\right)$. Values of $\mathrm{R}^{2}$ obtained from the isotherm models presented in Table I indicated that the highest correlation coefficient was obtained with the Langmuir isotherm model with $\mathrm{R}^{2}>0.90$ among the models studied. Further assessment was done by comparing the theoretical plots obtained from each isotherm to the experimental data of chromium sorption onto the adsorbents. This was assessed 
by the plot of $q_{e}$ (amount of chromium biosorbed per unit mass of the adsorbent $(\mathrm{mg} / \mathrm{g})$ ) against $c_{e}$ (concentration of chromium remaining in solution $(\mathrm{mg} / \mathrm{l})$ ) as shown in Figure I and Figure II. The Langmuir isotherm model showed the best description of the sorption process among the isotherm models; it displayed the highest conformity to the experimental values as very little variance was displayed between its predicted and experimental values. The Temkin isotherm model showed the poorest as displayed in the high variance between its theoretical $q_{e}$ values and the experimental $q_{e}$ values. Thus, it can be concluded that biosorption onto RHA and RHS biosorbents is monolayer coverage of the biosorbents surface by chromium ion.

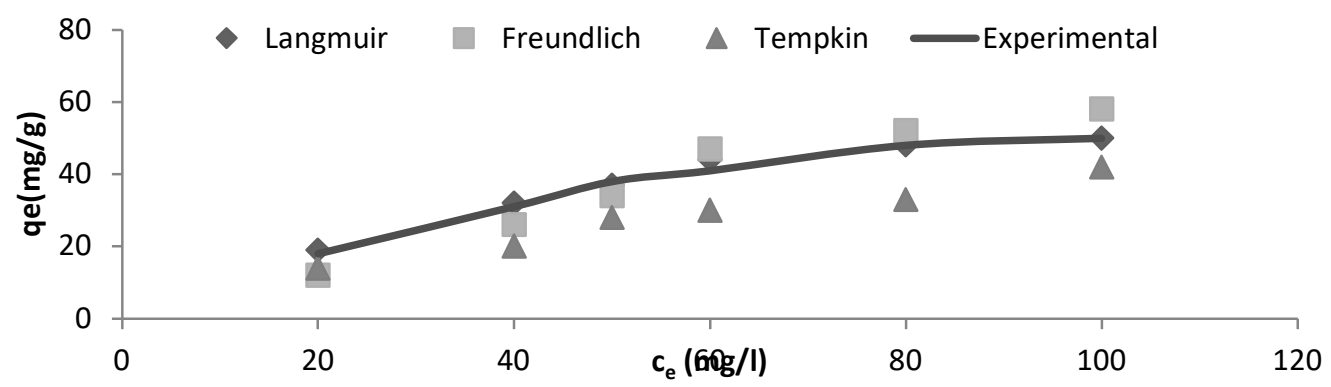

Figure I: Plots of Equilibrium Isotherms for Cr (VI) Removal by RHA

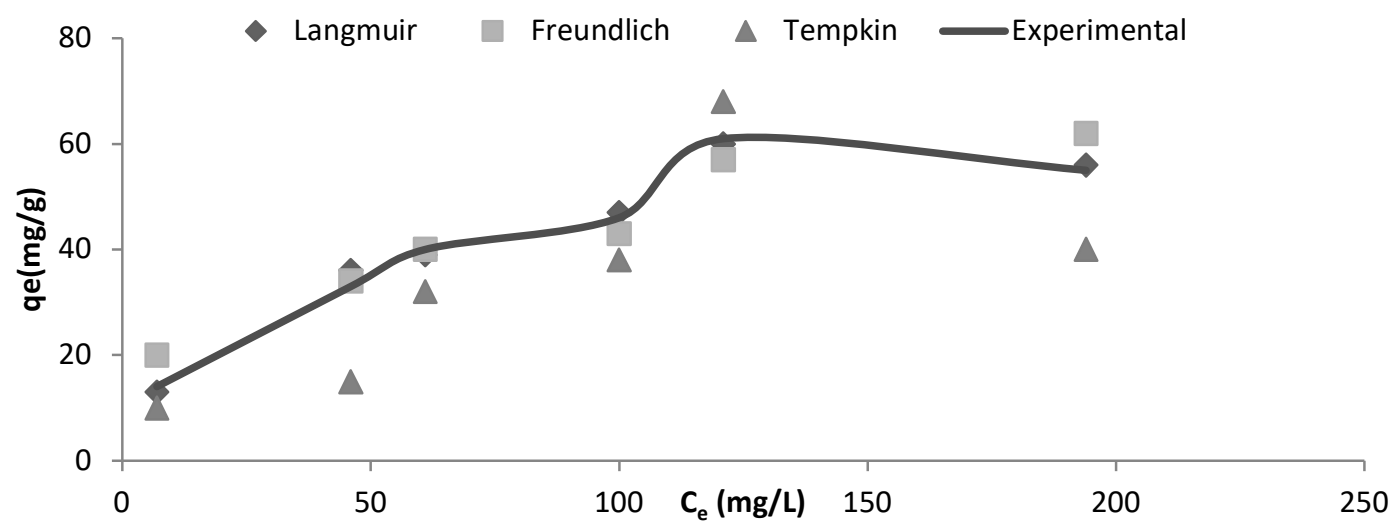

Figure II: Plots of Equilibrium Isotherms for Cr (VI) Removal by RHS

b. Effect of Adsorbent Dosage

The effect of adsorbent dosage on the sorption of $\mathrm{Cr}$ (VI) ions onto the adsorbents (RHA and RHS) was assessed via isotherm experiment at varied dosages of the adsorbent $(0.1-1.0 \mathrm{~g})$ and the result obtained is presented in Figure II. The results showed that the amount (\%) of $\mathrm{Cr}(\mathrm{VI})$ removed from the system increases with adsorbent dosage increment. As the adsorbent dosage increases there is a corresponding increase in the number of active sites available for adsorption of the adsorbate per unit volume of solution, which leads to an increase in the removal efficiency. There was increase in percentage removal from $0.4 \%$ to $39 \%$ for RHA and $18 \%$ to $58 \%$ for RHS as the dosage was increased from $0.1 \mathrm{~g}$ to $0.5 \mathrm{~g}$ but it became negligible at a higher adsorbent dose ( $>6 \mathrm{~g})$ as a result of setting in of equilibrium and then saturation of the adsorbent surface with the adsorbate ions which makes removal efficiency to become almost constant. Furthermore, it could be observed that RHS was more effective than RHA as observed by the amount (\%) removal achieved which is as a result of its higher surface area as determined by the Sears method (see Table II). The high RHS surface provides more active sites (areas) for the chromium ions to interact with. Hence, increase in percentage removal.

Table II: Surface area and pHpzc of RHS and RHA.

\begin{tabular}{lcl}
\hline Rice Husks & Surface Area $\left(\mathbf{m}^{2} / \mathbf{g}\right)$ & $\mathbf{p H}_{\mathbf{p z c}}$ \\
\hline$R H A$ & 211 & 8.9 \\
$R H S$ & 260 & 4.6 \\
\hline
\end{tabular}




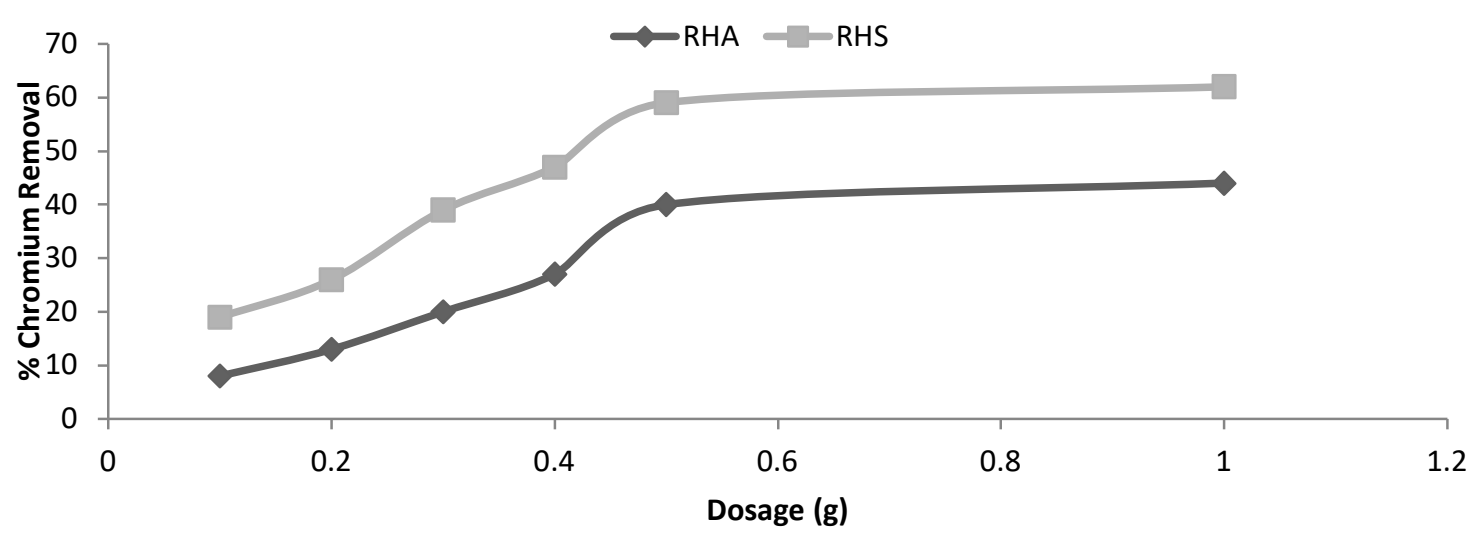

Figure II: Plots of Effect of Adsorbent Dosage on Cr (VI) Removal by RHS and RHA

\section{c. Effect of Initial Solution pH.}

The influence of the initial chromate solution $\mathrm{pH}\left(\mathrm{pH}_{\mathrm{o}}\right)$ studied at a $\mathrm{pH}$ range of 2-11 on the extent of its adsorption by the adsorbents is shown in Figure III. The results obtained showed that the amount of chromium ion removed increased per gram of the adsorbents as the $\mathrm{pH}_{0}$ was increased. At solution $\mathrm{pH}>6$, biosorption of $\mathrm{Cr}$ (VI) was higher compared to $\mathrm{pH}<4$. Hexavalent chromate removal from solution increased from $3 \%$ at $\mathrm{pH}$ of 2 to $39 \%$ at $\mathrm{pH}$ of 11 for RHA, and from $9 \%$ at $\mathrm{pH} 2$ to $47 \%$ at $\mathrm{pH} 11$ for RHA. The efficiency of a sorption process is basically affected by $\mathrm{pH}$ due to its influence on both the adsorbate and adsorbent moieties: it affects the degree of ionization and speciation of the adsorbate and the surface charge of the adsorbents (Zarrabi et al., 2014).

To understand the adsorption mechanism, it is necessary to determine the point of zero charge $\left(\mathrm{pH}_{\mathrm{PZC}}\right)$ of the adsorbent. The $\mathrm{pH}$ value at which the surface charge is zero is called the point of zero charge (pHpzc). When the $\mathrm{pH}<\mathrm{pHpzc}$ the surface of the adsorbent is positive and is favoured for adsorption of anions while at $\mathrm{pH}>\mathrm{pHpzc}$, the surface is positive and cations adsorption is favoured. In the present study, the $\mathrm{pH}_{\mathrm{Pzc}}$ obtained for the adsorbents was found to be 8.9 and 4.6 for RHA and RHS respectively. As the initial pH of the adsorbate increases, the surface of the adsorbent become negatively charged, which favours electrostatic interaction with the cationic chromium ions in solution. This explains why biosorption of the chromium ions increased with increase in initial solution $\mathrm{pH}$ and the amount removed (\%) in alkaline environments was higher than in the acidic environment.

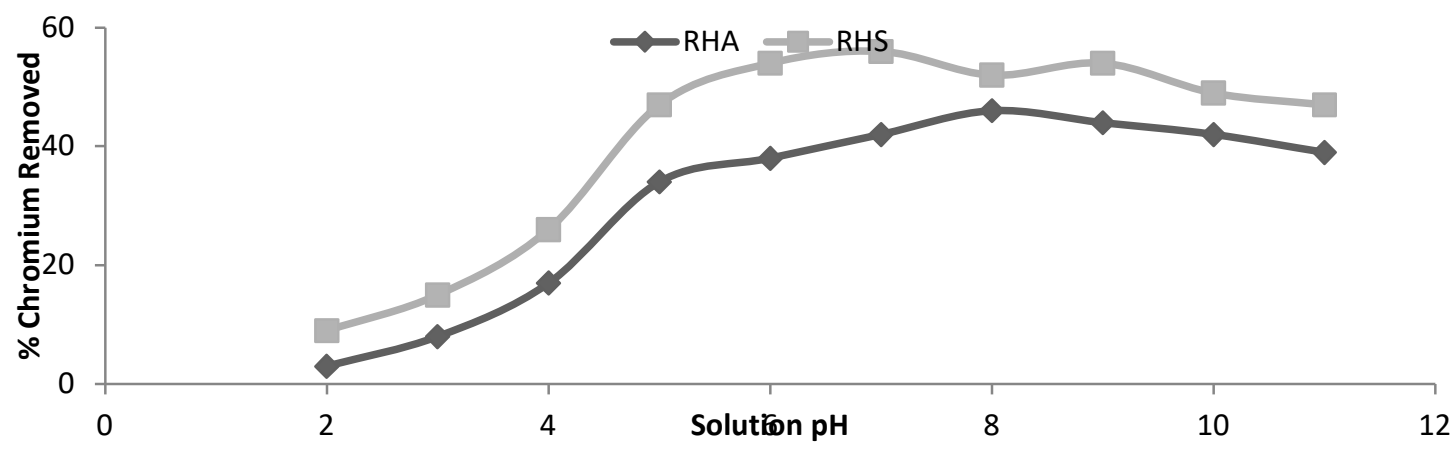

Figure III: Plots of Effect of Initial Solution pH on Cr (VI) Removal by RHS and RHA

\section{Estimation of Energy of Sorption}

Experimental sorption data obtained from the equilibrium isotherm studies was fitted into the Dubinin Radushkevich (DR) equation (8) to estimate the energy of the sorption process of Cr (VI) onto the adsorbents (RHS and IRS). The DR linear isotherm equation is expressed as:

$\ln q_{e}=\ln q_{m}-\mathrm{K}_{\mathrm{DR}} \varepsilon^{2}$

Where, $q_{m}(\mathrm{~mol} / \mathrm{g})$ is DR saturation capacity and $\mathrm{K}_{\mathrm{DR}}$ is the DR constant related to adsorption energy $\left(\mathrm{mol}^{2} / \mathrm{kJ}^{2}\right) . \varepsilon$ (Polanyi potential) is calculated as:

$\varepsilon=R T\left(1+\frac{1}{c e}\right)$

The DR parameters $q_{m}$ and $k$, calculated from the intercept and slope of the plots of $\ln q_{e}$ against $E^{2}$ were 66.0724 $\mathrm{mol} / \mathrm{g}$ and $0.00012 \mathrm{~mol}^{2} / \mathrm{kJ}^{2}$ for RHS and $51.7815 \mathrm{~mol} / \mathrm{g}$ and $0.000008 \mathrm{~mol}^{2} / \mathrm{kJ}^{2}$ for RHA, respectively. Elucidation of the energy of sorption process is evaluated by determining the mean free energy of adsorption $\left(\mathrm{E}_{\mathrm{DR}}\right)$. $\mathrm{E}_{\mathrm{DR}}(\mathrm{J} / \mathrm{mol})$ is the free energy change per molecule of the adsorbate when transferred from infinity in solution to the surface of the active sites of the adsorbent (Slivijic et al., 2009). $E_{D R}$ is calculated as follows: 
$E_{D R}=\frac{1}{\sqrt{2 \mathrm{~K}_{\mathrm{DR}}}}$

According to Pils and Laird 2007, the magnitude of $E_{D R}$ determines and classifies the type of adsorption as chemisorption or physisorption. A physisorption process has the value of $E_{D R}$ ranging between $1-16 \mathrm{~kJ} / \mathrm{mol}$, while adsorption processes with $E_{D R}$ magnitude greater than $16 \mathrm{~kJ} / \mathrm{mol}$ is termed chemisorption. The $E_{D R}$ obtained for the sorption of $\mathrm{Cr}$ (VI) onto RHS was $290.22 \mathrm{~kJ} / \mathrm{mol}$ and $119.09 \mathrm{~kJ} / \mathrm{mol}$ for RHA, respectively. The values of $E_{D R}$ obtained for sorption process in this study is greater than $16 \mathrm{~kJ} / \mathrm{mol}$, an indication that the mechanism of interaction between the adsorbent and the adsorbate is chemisorption. This is an indication of chemisorption as the prevailing mode of interaction between the sorbate $\mathrm{Cr}$ (VI) and adsorbents as confirmed from the kinetic of sorption studies (reported elsewhere) in which pseudo second order kinetic model prevailed.

\section{Conclusion}

The present study shows that the RHS and RHA are effective adsorbents for the removal of Cr (VI) from aqueous solution. Higher percentage of the adsorbate removal by RHA and RHS were possible provided that the initial chromate solution concentration ( $\mathrm{co}$ ) was low. Optimum conditions for $\mathrm{Cr}$ removal were found to be $\mathrm{pH}_{\mathrm{o}}>6$, adsorbent dosage $=0.5 \mathrm{~g} / 200 \mathrm{ml}$ of solution of solution for $\mathrm{Cr}$ concentration up to $500 \mathrm{mg} / \mathrm{L}$. The equilibrium between adsorbate in the solution and on the adsorbent surface was practically achieved in $2 \mathrm{~h}$. The Langmuir models suits the experimental data better than other models considered with maximum adsorption capacities of RHA and RHS been found to be $55.98 \mathrm{mg} / \mathrm{g}$ and $67.45 \mathrm{mg} / \mathrm{g}$ respectively. The abundance and affordable (cheap) cost of rice husks justifies its use as a precursor in the preparation of rice husk ash and silica as effective adsorbents for chromium removal from industrial effluents.

\section{Conflict of Interest}

The authors wish to confirm that there are no known conflicts of interest associated with this publication and there has been no significant financial support for this work that could have influenced its outcome.

\section{References}

Gupta VK, Rastogi A. Biosorption of hexavalent chromium by raw and acid-treated green alga Oedogonium hatei from aqueous solutions. J. Hazard Mater. 1999;163:396-402.

Ofomaja AE, Unuabonah EI, Oladoja NA. Competitive modeling for the biosorptive removal of copper and lead ions from aqueous solution by Mansonia wood sawdust. Bioresource Technology. 2010; 101: 3844-3852

Gupta VK, Rastogi A, Nayak A. Adsorption studies on the removal of hexavalent chromium from aqueous solution using a low cost fertilizer industry waste material. J. Colloid Interf. Sci. 2010; 42:135-141.

Vieira MGA, Almeida Neto AF, Silva MGC, Carneiro CN, Melo Filho, AA. Influence of the system on adsorption of $\mathrm{Pb}$ (II) and $\mathrm{Cu}(\mathrm{II})$ by rice husks ash: Kinetic study. Chemical Engineering Transactions. 2011;24, 12131218.

Kumar PS, Ramakrishnan K, Kirupha SD, Sivanesan S. Thermodynamic and kinetic studies of cadmium adsorption from aqueous solution onto rice husk. Braz. J. Chem. Eng. 2010; 27 (2): 347-355.

Gibb HJ, Lees PS, Pinsky PF, Rooney BC. Lung cancer among workers in chromium chemical production. Am. J. Ind. Med. 2000; 38, 115-126.

Mojdeh OM, Kheireddine ASW, Daud-Saeid B. Removal of hexavalent chromium-contaminated water and wastewater: A review [J]. Water Air Soil Poll.. 2009; 200, 59-77.

EPA (Environmental Protection Agency). Environmental pollution control alternatives. 1990. EPA/ 625/5-90/025, EPA/625/4-89/023, Cincinnati, US.

Mutongo F, Kuipa O, Kuipa P. (2014). Removal of Cr(VI) from Aqueous Solutions Using Powder of Potato Peelings as a Low Cost Sorbent. Bioinorganic Chemistry and Applications 7 pages http://dx.doi.org/10.1155/2014/973153

Sears GW. Determination of specific surface area of colloidal silica by titration with Sodium hydroxide. Anal. Chem. 1956; (28): 1981-1983.

Adelagun ROA, Itodo AU, Berezi EP, Oko OJ, Kamba EA, Andrew C, Bello HA. Adsorptive removal of $\mathrm{Cd}^{2+}$ and $\mathrm{Zn}^{2+}$ from aqueous system by BSG. J. Chem and Mat Res. 2014; (6):104-112

Mohanty K, Jha M, Meikap BC, Biswas MN. Removal of chromium (VI) from dilute aqueous solutions by activated carbon developed from Terminalia arjuna nuts activated with zinc chloride. Chemical Engineering Science. 2005; 60(11): 3049-3059.

Nakbanpote W, Goodman BA, Thiravetyan P. Cooper adsorption on rice husk derived materials studied by EPR and FTIR. Colloids Surf. A. 2007; 304: 7-13.

Weber TW, Chakravorti RK.. Pore and solid diffusion models for fixed-bed adsorbers. AlChE J. 1974; 20 (2): $228-238$.

Dubey SP, Gopal K. Adsorption of chromium (VI) on low cost adsorbents derived from agricultural waste 
material: a comparative study. Journal of Hazardous Materials 2007; 145(3): 465-470.

Baral SS, Das SN, Rath P. Cr (VI) removal from aqueous solution by adsorption on treated sawdust. Biochemical Engineering Journal. 2006; 31(3): 216-222. doi:10.1016/j.bej.2006.08.003.

Babu BV, Gupta S. Adsorption of Cr (VI) using activated neem leaves: Kinetic studies. Adsorption. 2008;14: 8592.

Karthikeyan T, Rajgopal S, Miranda LR. Chromium (VI) adsorption from aqueous solution by Hevea brasiliensis sawdust activated carbon. Journal of Hazardous Materials. 2005; 124 (1-3): 192-199.

Cimino G, Passerini A, Toscano G. Removal of toxic cations and $\mathrm{Cr}$ (VI) from aqueous solution by hazelnut shell. Water Research 2000 ; 34 (11): 2955-2962.

Zarrabi M, Soori MM, Spehr AA, Borji S, Ghaffari HR. Removal of phosphorus by ion exchange resins: Equilibrium, kinetics and thermodynamic studies. Environ. Engin. and Manag. Jou. .2014; 13 (4): 891-903

Šljivić M, Smičiklas I, Pejanović S, Plećaš I. Comparative study of $\mathrm{Cu}^{2+}$ adsorption on a zeolite, a clay and a diatomite from Serbia. Appl. Clay Sci. 2009; 43: 33-4.

Pils JR, Laird DA. Sorption of tetracycline and chlortetracycline on K- and Ca-saturated soil clays, humic substances, and clay-humic complexes Environ. Sci. Technol. 2007. 41, 1928-33 